\title{
Analisis Pengaruh Disiplin Kerja Dan Motivasi Kerja Karayawan CV. Adeeva Kontruksi Jambi
}

\author{
Indria Mayesti ${ }^{1}$, Abd.Halim ${ }^{2}$, Rika Neldawaty ${ }^{3}$, Des Arianti Syarah ${ }^{4}$ \\ ${ }^{1}$ BPSDM Provinsi Jambi \\ 2,3,4 Universitas Muhammadiyah Jambi
}

Email: Indriamayesti11@gmail.com, Abdh0074@gmail.com, Rikaneldawaty1079@gmail.com, Desariantisyarah@gmail.com

\begin{abstract}
Abstrak_ Tujuan dari penelitian ini yaitu menjelaskan Analisis Pengaruh Disiplin Kerja dan Motivasi Kerja Karyawan Jambi (Studi CV. Adeeva Kontruksi) Secara simultan dan parsial. Jenis penelitian yang dipergunakan penelitian ini adalah penelitian asosiatif yaitu bertujuan untuk mengetahui hubungan antara dua variabel atau lebih. Adapun variabel yang dimaksud dalam penelitian ini yaitu variabel X1( Motivasi Kerja ), variabel X2 ( Disiplin Kerja) dan Y ( Kinerja). Hasil penelitian berdasarkan hasil regresi linier berganda terbukti bahwa secara simultan dan parsial variabel Kinerja, Disiplin, dan Motivasi berpengaruh signifikan terhadap Kinerja Karyawan (Studi CV. Adeeva Kontruksi). Berdasarkan hasil penelitian rekomendasi yang diharapkan dapat menjadi masukan Hendaknya pihak PT Adeeva menjadikan disiplin kinerja merupakan bagian utama di dalam perusahaan agar kegiatan perusahaan bisa berjalan lebih baik lagi. Dan perlunya motivasi kepada seluruh karyawan untuk bekerja lebih baik lagi kedepannya dengan memberikan reward kepada karyawan yang berprestasi agar memberikan motivasi kepada seluruh karyawan untuk berkerja lebih baik lagi.
\end{abstract}

Kata Kunci: Kinerja, Disiplin, dan Motivasi

Abstract_The purpose of this research is to explain the analysis of the influence of work discipline and work motivation of Jambi employees (CV. Adeeva Construction Study) simultaneously and partially this type of research used in this research is associative research which aims to determine the relationship between two or more variables. The variables referred to in this study are variable X1 (Work Motivation), variable X2 (Work Discipline) and Y (Performance). The results of the study based on the results of multiple linear regressions proved that the variables of Performance, Discipline, and Motivation had a significant effect on Employee Performance (CV. Adeeva Construction Study). Based on the research results that are expected to be input, PT Adeeva should make performance performance a major part of the company so that the company's activities can run even better. And the need for motivation to all employees to work better in the future by giving rewards to employees who excel in order to motivate all employees to work better.

Keywords: Performance, Discipline, and Motivation

\section{PENDAHULUAN}

CV. Adeeva Konstruksi Jambi sebagai General Supplier memfokuskan bisnis dalam pengadaan jenisjenis alat berat dan material pendukung pekerjaan proyek konstruksi besar ataupun kecil. Perusahaan ini telah berpengalaman dan bekerja sama dengan partner-partner bisnis terpercaya. Perusahaan ini memiliki jumlah karyawan sebanyak 25 orang dimana perusahaan sangatlah memerlukan karyawan yang lebih termotivasi dan disiplin kerja di dalam perusahaan seperti tidak sering membolos dengan berbagai macam alasan, dapat memanfaatkan waktu kerja dengan sebaik-baiknya, tidak melakukan penyimpangan saat jam kerja (menggunakan telepon perusahaan, internet perusahaan dan lain-lain yang tidak ada hubungannya dengan kegiatan perusahaan) dan meningkatkan produktivitas perusahaan.

Tujuan dari semua perusahaan adalah untuk mencapai keuntungan maksimal, oleh karena itu untuk mewujudkan tujuan dari perusahaan haruslah didukung oleh kemampuan (skill) dari karyawannya dalam bekerja. Tingkat disiplin kerja karyawan dan motivasi kerja karyawan akan sangat mempengaruhi kinerja karyawan dan berpengaruh terhadap produktivitas sebuah perusahaan.

\section{Pengertian Kinerja}

Pengertian kinerja merupakan suatu hasil kerja yang dihasilkan oleh seorang pegawai diartikan untuk mencapai tujuan yang diharapkan. Suatu organisasi perusahaan didirikan karena mempunyai tujuan tertentu yang ingin dan harus dicapai. Dalam mencapai tujuannya setiap organisasi dipengaruhi perilaku organisasi. Salah satu kegiatan yang paling lazim dilakukan dalam organisasi adalah kinerja karyawan, yaitu bagaimana ia melakukan segala sesuatu pekerjaan atau peranan dalam organisasi.

\section{Pengertian Disiplin}

Menurut Singodimedjo dalam buku Edy Sutrisno (2009) mengatakan disiplin adalah sikap kesediaan dan kerelaan seseorang untuk mematuhi dan menaati normanorma peraturan yang berlaku disekitarnya. Disiplin karyawan yang baik akan mempercepat tujuan perusahaan, sedangkan disiplin yang merosot akan menjadi penghalang dan memperlambat pencapaian tujuan perusahaan.

\section{Pengertian Motivasi}

Menurut Hasibuan (2013) motivasi mempersoalkan bagaimana cara mendorong gairah kerja 
bawahan, agar mereka mau bekerja keras dengan memberikan semua kemampuan dan keterampilan untuk mewujudkan tujuan perusahaan.

\section{Metodelogi Penelitian}

Karena penelitian ini bertujuan untuk mengetahui pengaruh motivasi kerja dan disiplin keija terhadap kinerja karyawan CV. Adeeva Konstruksi Jambi. Jenis penelitian yang dipergunakan penelitian ini adalah penelitian asosiatif yaitu bertujuan untuk mengetahui hubungan antara dua variabel atau lebih. Adapun variabel yang dimaksud dalam penelitian ini yaitu variabel X1( Motivasi Kerja ), variabel X2( Disiplin Kerja) dan $Y$ ( Kinerja) $Y=\alpha+\beta_{1} X_{1}+\beta_{2} X_{2}+e$.

\section{Hasil Penelitian}

Penelitian ini ingin melihat bagaimana pengaruh disiplin dan motivasi kerja terhadap kinerja karyawan CV Adeeva Konstruksi Jambi, setelah dilakukan kegiatan pengolahan data untuk menjawab perumusan masalah dalam penelitian ini, dapat dilihat pada pembahasan dibawah ini.

Validitas menunjukkan sejauh mana alat pengukur yang dipergunakan untuk mengukur apa yang diukur. Adapun caranya adalah dengan mengkorelasikan antara skor yang diperoleh pada masing-masing item pertanyaan dengan skor total individu. Pengujian validitas dilakukan dengan bantuan komputer menggunakan program SPSS for Windows Versi 22.0. Dalam penelitian ini pengujian validitas hanya dilakukan terhadap 25 responden. Pengambilan keputusan berdasarkan pada nilai rhitung (Corrected Item-Total Correlation) $>$ rtabel sebesar 0,396 , untuk $\mathrm{df}=25-3=$ 22; $\alpha=0,05 \mathrm{maka}$ item/ pertanyaan tersebut valid dan sebaliknya.

Tabel 1. Hasil Uji Validitas

\begin{tabular}{|l|r|l|l|l|r|}
\hline \multicolumn{1}{|c|}{$\begin{array}{c}\text { Nilai Corrected } \\
\text { Corelation/ } \\
\text { hitung }\end{array}$} & Item & Sig & rtabel & Kriteria \\
\hline Kinerja & 0,883 & & 0,000 & 0,378 & Valid \\
Disiplin & 0,787 & & 0,000 & 0,378 & Valid \\
\hline
\end{tabular}

\begin{tabular}{l|r|r|r|r|} 
Motivasi & 0,815 & 0,000 & 0,378 & Valid \\
\hline Sumber : Data Primer Yang Diolah.
\end{tabular}

Berdasarkan Tabel 1 maka dapat dilihat bahwa seluruh pertanyaan untuk variabel dalam penelitian ini memiliki status valid, karena nilai rhitung (Corrected Item-Total Correlation) > rtabel sebesar 0,378

\section{Uji Reliabilitas}

Uji reliabilitas dilakukan terhadap item pertanyaan yang dinyatakan valid. Suatu variabel dikatakan reliabel atau handal jika jawaban terhadap pertanyaan selalu konsisten. Koefisien reliabilitas instrumen dimaksudkan untuk melihat konsistensi jawaban butir-butir pernyataan yang diberikan oleh responden Adapun alat analisisnya menggunakan metode belah dua (split half) dengan mengkorelasikan total skor ganjil lawan genap, selanjutnya dihitung reliabilitasnya menggunakan rumus "Alpha Cronbach'. Penghitungan dilakukan dengan dibantu komputer program SPSS. Adapun reliabilitas untuk masing-masing variabel hasilnya disajikan pada tabel berikut ini.

Tabel 2. Hasil Uji Reliabilitas

\begin{tabular}{|c|r|r|r|l|}
\hline No & Variabel & ralpha & rkritis & Kriteria \\
\hline 1 & Kinerja & 0,929 & 0,600 & Reliabel \\
2 & Disiplin & 0,947 & 0,600 & Reliabel \\
3 & Motivasi & 0,907 & 0,600 & Reliabel \\
\hline
\end{tabular}

Sumber : Data Primer Yang Diolah

Berdasarkan Tabel 2. uji reliabilitas dilakukan terhadap item pertanyaan yang dinyatakan valid. Suatu variabel dikatakan reliabel atau handal jika jawaban terhadap pertanyaan selalu konsisten. Jadi hasil koefisien reliabilitas instrument kinerja adalah sebesar rll $=0,929$, instrument disiplin adalah sebesar rll $=0,947$, motivasi adalah sebesar rll $=0,907$, ternyata memiliki nilai "Alpha Cronbach" lebih besar dari 0,600, yang berarti ketiga instrumen dinyatakan reliable atau memenuhi persyaratan.

Tabel 3

Coefficients $^{\mathrm{a}}$

\begin{tabular}{|ll|r|r|r|r|r|}
\hline \multirow{2}{*}{ Model } & \multicolumn{2}{|c|}{ Unstandardized Coefficients } & Standardized Coefficients & \\
\cline { 2 - 6 } & \multicolumn{1}{|c|}{ B } & Std. Error & Beta & \multicolumn{1}{c|}{ Sig. } \\
\hline 1 & (Constant) & 26.537 & 9.499 & 2.794 & .003 \\
& Disiplin kerja & .628 & .413 & .359 & 2.520 & .000 \\
& Motivasi kerja & .770 & 2.654 & .602 & 2.551 & .004 \\
\hline
\end{tabular}

a. Dependent Variable: Kinerja karyawan.

$\mathrm{Y}=26.537+0.628 X_{1}+0.770 X_{2}$ Nilai konstan sebesar 26.537 artinya jika disiplin kerja dan motivasi kerja tidak mempunyai pergerakan atau berlaku konstan selama penelitian maka kinerja karyawan selama penelitian ini dilakukan adalah sebesar 26.537 satuan.
Nilai koefisien regresi variabel disiplin kerja bernilai positif, yaitu 0.628 artinya setiap terjadi peningkatan disiplin kerja sebanyak $1 \%$, maka akan berpengaruh terhadap kinerja kayawan sebesar $62,8 \%$ dengan asumsi variabel independen lain nilainya tetap. 
Nilai koefisien regresi variabel motivasi kerja bernilai positif, yaitu 0.770 artinya setiap ada peningkatan motivasi kerja sebesar $1 \%$, maka akan berpengaruh terhadap kinerja karyawan sebesar 77,0\% dengan asumsi variabel independen lain nilainya tetap.

Tabel 4

Model Summary

\begin{tabular}{|l|r|r|r|r|}
\hline Model & \multicolumn{1}{|c|}{ R } & \multicolumn{1}{c|}{ R Square } & Adjusted R Square & Std. Error of the Estimate \\
\hline 1 & $.911^{\mathrm{a}}$ & .831 & .788 & .20429 \\
\hline
\end{tabular}

a. Predictors: (Constant), harga, kualitas layanan

Nilai koefisien determinasi $\left(\mathrm{R}^{2}\right)$ sebesar 0.831 . ini menunjukan bahwa 83.1 persen kinerja karyawan dipengaruhi oleh disiplin kerja dan motivasi kerja sedangkan 16.9 persen dijelaskan oleh faktor-faktor lain yang tidak dibahas dalam model ini. Untuk nilai $\mathrm{R}$ sebesar 0.911, ini menunjukan bahwa 91.1 persen menunjukan terdapat hubungan yang sangat signifikan antara disiplin kerja dan motivasi kerja terhadap kinerja karyawan.

\section{Pengujian Hipotesis Uji T}

Uji T digunakan untuk mengetahui apakah secara parsial disiplin dan kinerja berpengaruh atau tidak terhadap kinerja karyawan CV Adeeva Konstruksi Jambi. Pengujian menggunakan tingkat signifikasi 0,05 .

Untuk mengetahui apakah variabel bebas secara individu berpengaruh atau tidak terhadap kinerja karyawan CV Adeeva Konstruksi Jambi, maka dilakukan pengujian secara parsial. Dengan menggunakan uji $\mathrm{t}$ untuk nilai $\mathrm{t}$ hitung pada derajat kebebasan (a-k) dengan derajat keyakinan sebesar 0.05 persen maka diperoleh nilai t tabel sebesar 1.859

Nilai t hitung $\mathrm{X}_{1}$ (disiplin kerja) sebesar 2.520 lebih besar dari nilai t tabel yakni $(2.520>1.859)$ maka Ho ditolak dan $\mathrm{Ha}$ diterima, artinya disiplin kerja berpengaruh positif dan signifikan terhadap kinerja karyawan CV Adeeva Konstruksi Jambi, dan ini sesuai dengan hipotesis yang telah di tulis sebelumnya. Untuk $\mathrm{X}_{2}$ (motivasi kerja) nilai $\mathrm{t}$ hitung diperoleh sebesar 2.551 dengan nilai $\mathrm{t}$ tabel yakni 1.859 atau (2.551> 1.859) maka Ho diterima dan Ha ditolak, artinya motivasi kerja secara parsial mempengaruhi kinerja karyawan CV Adeeva Konstruksi Jambi.

\section{Uji $F$}

Uji F yaitu uji koefisien regresi secara bersamasama untuk menguji signifikasi pengaruh beberapa variabel independen terhadap variabel dependen. Pengujian menggunakan tingkat signifikasi 0.05.

Tabel 5

ANOVA ${ }^{\mathrm{a}}$

\begin{tabular}{|ll|r|r|r|r|r|}
\hline Model & & Sum of Squares & df & Mean Square & F & Sig. \\
\hline 1 & Regression & 1.638 & 2 & .819 & 19.624 & $.001^{\mathrm{b}}$ \\
& Residual & .334 & 30 & .042 & & \\
& Total & 1.972 & 32 & & & \\
\hline
\end{tabular}

a. Dependent Variable: kinerja karyawan

b. Predictors: (Constant), disiplin kerja, motivasi kerja

Pada tingkat keyakinan 0.05 persen diperoleh nilai $\mathrm{f}$ tabel sebesar 4.46 sedangkan nilai $\mathrm{f}$ hitung sebesar 19.624 sehingga dapat dilihat nilai $\mathrm{F}$ hitung lebih besar dari nilai $f$ tabel $(19.624>4.46)$ sehingga Ho diterima dan Ha ditolak, ini berarti disiplin kerja dan motivasi kerja secara bersama-sama mempunyai pengaruh yang signifikan terhadap kinerja karyawan CV Adeeva Konstruksi Jambi.

\section{SIMPULAN}

Berdasarkan hasil penelitian dan pembahasan maka kesimpulan yang dapat dikemukakan dalam penelitian ini adalah: Hasil hitungan regresi linier berganda untuk disiplin kerja menunjukan bahwa disiplin kerja mempunyai pengaruh yang positif dan signifikan terhadap kinerja karyawan CV Adeeva Konstruksi Jambi dengan koefisien regresi sebesar 0.628 dan nilai signifikansi sebesar 0.000 , Hasil hitungan regresi linier berganda untuk motivasi kerja menunjukan bahwa variabel motivasi kerja mempunyai pengaruh yang Positif dan Signifikan, dengan didapati nilai Koefisien regresi linier berganda sebesar 0.770 dengan tingkat signifikansi sebesar 0,004

\section{DAFTAR PUSTAKA}

A.A Anwar Prabu Mangkunegara. 2009. Evaluasi Kinerja Sumber Daya Manusia. Bandung: Penerbitan Refika Aditama

Arikunto, Suharsimi. 2006. Prosedur Penelitian Suatu Pendekatan Praktik. Jakarta: Reneka Cipta 
Arsani. 2015. Pengaruh motivasi dan disiplin kerja terhadap kinerja karyawan departemen Jasa alat berat pada PT. Pusri Palembang, -E. UMP: skripsi tidak dipublikasikan

Augusty, Ferdinand. 2006. Metode Penelitian Manajemen. Semarang: Universitas Diponegoro

Griffin, Jill. 2003. Manajemen Sumber Daya Manusi. Jakarta: Salemba Empat

Hasibuan, Malayu S. P. 2006. Manajemen: Dasar, Pengertian, dan Masalah. Edisi Revisi. Jakarta: Bumi Aksara.

Hasibuan, Malayu S. P. 2007. Organisasi dan Motivasi Dasar Peningkatan Produktivitas. Jakarta: PT. Bumi Aksara

Hasibuan, Malayu S. P. 2008. Manajemen Sumber Daya Manusia. Edisi Revisi, Cetakan Tiga Belas, Bumi Aksara. Jakarta

Hasibuan, Malayu S.P. 2009. Manajemen Sumber Daya Manusia. Edisi Revisi, Cetakan Ketiga Belas. Jakarta: PT. Bumi Aksara

Hasibuan, Malayu S. P. 2013. Manajemen Sumber Daya Manusia. Edisi Revisi. Jakarta: PT. Bumi Aksara

Handoko, Hani T. 2013. Manajemen. Jakarta: BPFE

Hoetomo. 2005. Kamus Lengkap Bahasa Indonesia. Surabaya: Mitra Pelajar

Mathis, L. R. dan J. H. Jackson. 2010. Human Resource Management. $13^{\text {th }}$ Edition. South Western: Joseph Sabatino

Iqbal, Hasan M. 2013. Analisis Data Penelitian Dengan Statistik. Jakarta: Bumi Aksara

Moenir. 2004. Manajemen Pelayanan Umum. Jakarta: Bumi Aksara

Nurmaliani. 2015. Pengaruh disiplin kerja dan motivasi kerja terhadap kinerja karyawan pada PT. Thamrin Brothers Palembang, F-E. UMP : skripsi tidak dipublikasikan

Mahmudi. 2010. Manajemen Kinerja Sektor Publik. Jakarta: STIE YKPN

Phil, Wibowo M. 2013. Manajemen Kinerja. Jakarta: Raja grafindo persada

Rivai, Veithzal. 2004. Manajemen Sumber Daya Manusia Untuk Perusahaan. Edisi Pertama. Jakarta: PT. Raja Grafindo Persada

Rivai, Veithzal. 2011. Manajemen Sumber Daya Manusia Untuk Perusahaan. Edisi Kedua. Jakarta: PT. Raja Grafindo Persada

Robbin, S. P. 2011.Perilaku Organisasi. Versi Bahasa Indonesia. Edisi Dua Belas. Jakarta: Salemba Empat

Setyawan dan Waridin. 2006. Pengaruh Disiplin Kerja Karyawan dan Budaya Organisasi Terhadap Kinerja di Divisi Radiologi RSUP Dokter Kariadi Semarang

Sedarmayanti. 2009. Sumber Daya Manusia dan Produktivitas Kerja. Bandung: Mandar Maju

Sedarmayanti. 2011. Tata Kerja dan Produktifitas Kerja. Cetakan Ketiga. Bandung: Mandar Maju
Siagan, Sondang P. 2003. Manajemen Sumber Daya Manusia. Edisi satu, Ceetakan Kesepuluh. Jakarta: Bumi Aksara

Siagan, Sondang P. 2008. Manajemen Strategi. Jakarta: Bumi Aksara

Simamora, Henry. 2004. Manajemen Sumber Daya Manusia. Yogyakarta: STIE YKPN

Simamora, Henry. 2006. Manajemen Sumber Daya Manusia. Edisi Ketiga.

Yogyakarta: STIE YKPN

Sugiyono. 2010. Metodelogi Penelitian Bisnis. Bandung: Alfabeta

Sugiyono. 2011. Metodelogi Penelitian Kuantitatif Kualitatif dan R\&D. Jakarta:

Alfabeta

Sugiyono. 2012. Metodelogi Penelitian Bisnis. Bandung: Alfabeta

Sugiyono. 2013. Metodelogi Penelitian Kuantitatif Kualitatif. Bandung: Alfabeta

Sutrisno, Edi. 2009. Manajemen Sumber Daya Manusia. Edisi Pertama, Jakarta: Kencana Prenada Media Group

Wibowo. 2010. Manajemen Kinerja. Jakarta: Rajawali Press

Wibowo. 2011. Manajemen Kinerja. Jakarta: Raja Grafindo Persada

Wirawan. 2009. Evaluasi Kinerja Sumber Daya Manusia. Jakarta: Salemba Empat 